$>$ La glycosylation est un processus cellulaire complexe conduisant à des transferts successifs de monosaccharides sur une molécule acceptrice, le plus souvent une protéine ou un lipide. Ce processus est universel chez tous les organismes vivants et est très conservé au cours de l'évolution. Chez l'homme, des perturbations survenant au cours d'une ou plusieurs réactions de glycosylation sont à l'origine de glycopathologies génétiques rares, appelées anomalies congénitales de la glycosylation ou congenital disorders of glycosylation (CDG). Cette revue propose de revisiter ces CDG, de 1980 à aujourd'hui, en présentant leurs découvertes, leurs diagnostics, leurs causes biochimiques et les traitements actuellement disponibles. <

\section{Le processus de glycosylation :} entre acteurs et régulateurs

Les acteurs au cœur de la réaction de glycosylation La glycosylation est une modification post-traductionnelle à laquelle différents acteurs participent: (1) des enzymes de glycosylation (glycosyltransférases [GT] et glycosylhydrolases [GH]), (2) différents nucléotides sucres mono/diphosphate (NM/DP-sucres), (3) des transporteurs de nucléotides sucres (TNS), et (4) des molécules acceptrices, le plus souvent une protéine, un lipide ou un monosaccharide. Ces réactions se déroulent principalement dans le réticulum endoplasmique granuleux (REG) et/ou l'appareil de Golgi, possédant un environnement ionique spécifique, en termes de $\mathrm{pH}$ et d'ions divalents, nécessaire à l'activité des différentes GT pour la formation d'une liaison covalente entre un monosaccharide et la molécule acceptrice (Figure 1).

\section{Rôle des glycosyltransférases golgiennes dans} le transfert des nucléotides sucres mono/diphosphate Les glycosyltransférases (GT) sont les enzymes au cœur de la glycosylation. Selon leur structure, elles peuvent

Vignette (Marquage de la lectine VVL dans les cellules HEK déficientes pour TMEM 165, (c) Marine Houdou)

\title{
Anomalies congénitales de la glycosylation (CDG)
}

\section{0-2020, 40 ans pour comprendre}

Marine Houdou, François Foulquier

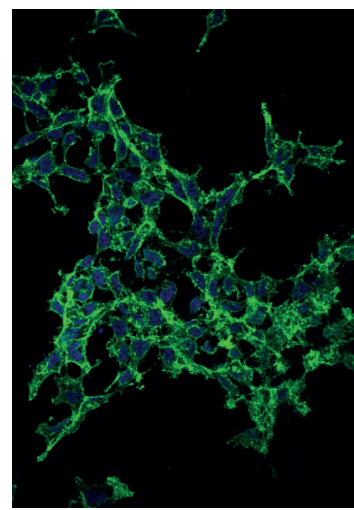

Univ. Lille, CNRS, UMR 8576 -

UGSF - Unité de glycobiologie structurale et fonctionnelle, Avenue Mendeleiev, 59655 Villeneuve d'Ascq, France. francois.foulquier@univ-lille.fr

être classées en deux grandes familles: les GT de type A (GT-A) et les GT de type B (GT-B). Les GT-A ont une conformation telle que les acides aminés constituant leur site catalytique forment un motif structural de type «pli Rossmann $»^{1}$ qui se retrouve communément dans la structure des protéines liant les nucléotides. Outre ce pli, les GT-A possèdent également dans leur structure un motif DXD ( $D$ étant un acide aspartique et $X$ n'importe quel acide aminé) permettant la liaison d'un ion divalent impliqué dans la stabilisation du nucléotide sucre diphosphate (NDP-sucre) au niveau du site catalytique de l'enzyme. La plupart de ces enzymes requièrent comme cofacteur le manganèse (sous forme ionique $\mathrm{Mn}^{2+}$ ) qui est essentiel pour leurs activités [1]. Les GT-B ne possèdent, quant à elles, pas de motif DXD et sont donc considérées comme des enzymes métal/ion-indépendantes. Les GT sont toutes des protéines transmembranaires de type II, dont le domaine catalytique, porté par la partie en C-terminal de la protéine, est exposé dans la lumière de l'appareil de Golgi. Ces enzymes possèdent différents degrés de spécificité selon que l'on considère le substrat «donneur », la molécule «acceptrice» et l'anomérie $(-\alpha$ ou $-\beta)$ de la liaison glycosidique qu'elles catalysent. Chez l'homme, les GT ont pour substrats donneurs les principaux NM/DP-sucres que sont: I'uridine diphosphate-glucose (UDP-GIc), I'UDP-galactose (UDP-Gal), I'UDP-N-acétylglucosamine (UDP-GIc$N A c$ ), I'UDP-N-acétylgalactosamine (UDP-GalNAc), I'UDP-acide glucuronique (UDP-GIcA), I'UDP-xylose (UDP-Xyl), le guanosine diphosphate-mannose (GDP-Man), le GDP-fucose (GDP-Fuc) et le

\footnotetext{
Structure composée d'un feuillet $\beta$ fait de 6 brins en parallèle, liés à deux paires d'hélice $\alpha$.
} 


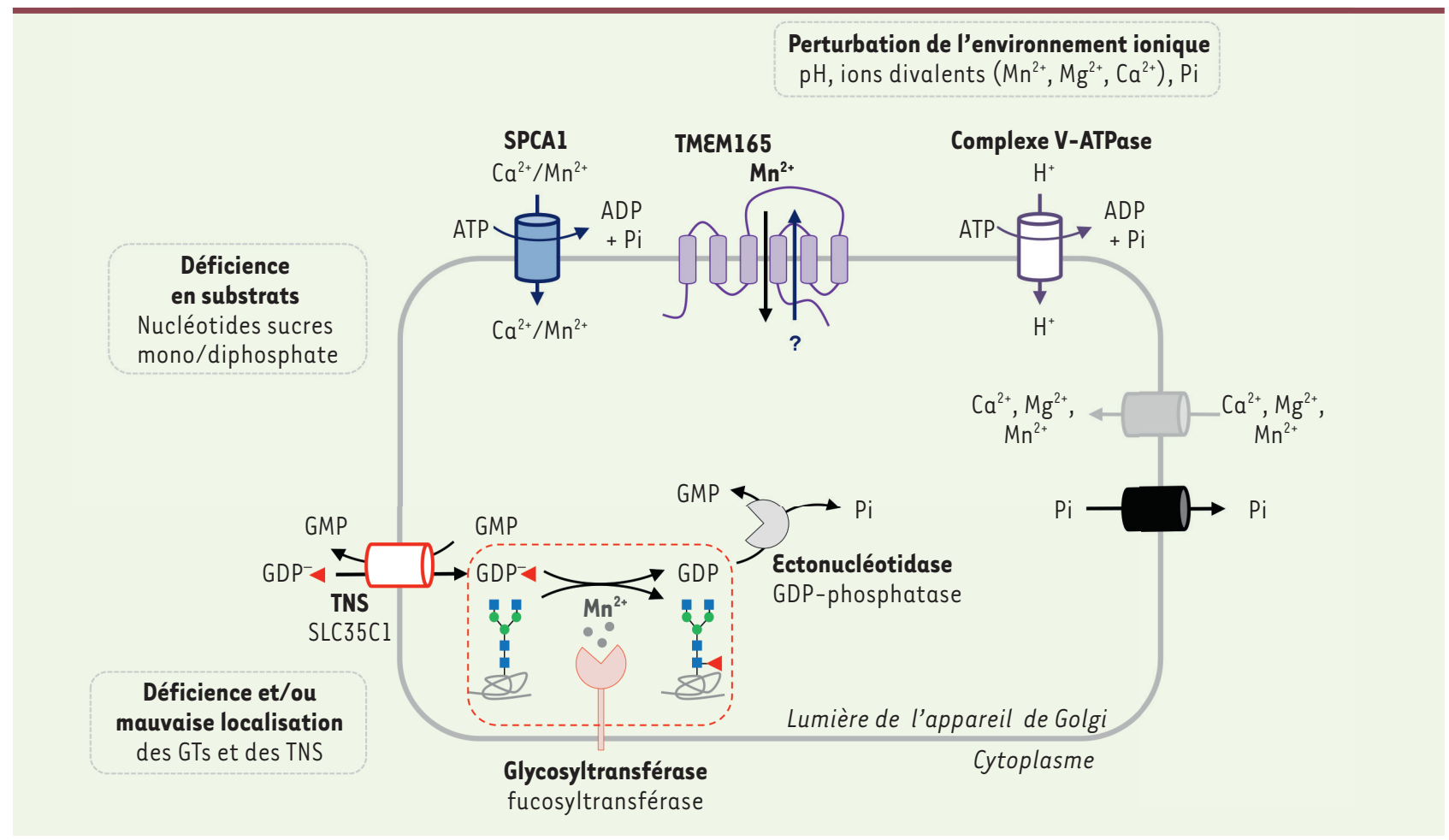

Figure 1. Acteurs principaux requis au cours d'une réaction de glycosylation dans la lumière de l'appareil de Golgi. La réaction de glycosylation met en jeu des acteurs primaires : une glycosyltransférase (GT), ici une fucosyltransférase ; un substrat donneur, le GDP-fucose et une molécule acceptrice, une $\mathrm{N}$-glycoprotéine (cadre en pointillé rouge). Cette figure illustre également les acteurs secondaires nécessaires à cette réaction, en particulier des éctonucléotidases, différents transporteurs de cations $\left(\mathrm{Mn}^{2+}, \mathrm{Mg}^{2+}, \mathrm{Ca}^{2+}\right)$, de protons $\left(\mathrm{H}^{+}\right)$et de phosphate inorganique ( $\mathrm{Pi}$ ). Les encadrés en pointillé gris indiquent les causes principales de dérégulation du processus de glycosylation, pouvant aboutir à des Congenital Disorders of Glycosylation (CDG). Le point d'interrogation représente un ion dont la nature reste à spécifier. SPCAl : secretory pathway $\mathrm{Ca}^{2+} / \mathrm{Mn}^{2+} \mathrm{ATPase}$; $\mathrm{SLC} 35 \mathrm{Cl}$ : solute carrier transporter 35C1; TMEMI 65 : transmembrane protein 165 ; TNS : transporteur de nucléotides sucres mono/diphosphate.

cytosine monophosphate-acide sialique (CMP-Sia). Tous ces monosaccharides dits «activés » sont préalablement synthétisés dans le cytoplasme à l'exception du CMP-Sia dont la dernière étape de synthèse se déroule dans le noyau. Une fois générés, ces NM/DP-sucres sont transportés par des transporteurs de nucléotides sucres qui leurs sont spécifiques.

\section{Import des nucléotides sucres}

\section{par les transporteurs golgiens de NM/DP-sucres}

Les transporteurs de NM/DP-sucres (TNS) sont des protéines transmembranaires appartenant à la famille très conservée des SLC35 (solute carrier transporter 35) [2]. Les TNS golgiens importent du cytoplasme dans la lumière de l'appareil de Golgi un NM/DP-sucre (NDP) et, simultanément, exportent la forme monophosphate du nucléotide (NMP) correspondant vers le cytoplasme. Ceci est permis grâce à l'action d'ectonucléotidases qui hydrolysent les NDP générés par la réaction de glycosylation en produisant le NMP et du phosphate inorganique ( $\mathrm{Pi}$ ) (Figure 1). La localisation subcellulaire de chaque transporteur est encore mal connue, mais elle est supposée calquer celle des GT afin que l'apport en nucléotides-sucres soit suffisant pour leurs activités.

\section{Rôle des glycosylhydrolases dans la maturation} et la dégradation des structures glycanniques

À côté des glycosyltransférases, les glycosylhydrolases (GH), ou glycosidases, sont également des enzymes clefs du processus de glycosylation, étant responsables de l'hydrolyse des liaisons glycanniques libérant un ou plusieurs monosaccharides. Leurs actions sont essentielles dans la maturation des structures glycanniques générées au cours de la $\mathrm{N}$-glycosylation. Ces enzymes ont également un rôle très important dans le recyclage de certains monosaccharides via la dégradation des structures glycanniques.

\section{La régulation de la glycosylation}

La glycosylation est un processus très conservé au cours de l'évolution. II est universel chez tous les organismes vivants, procaryotes et eucaryotes, unicellulaires et pluricellulaires. Néanmoins, au sein d'un même organisme, différentes voies de glycosylation coexistent, générant une grande diversité et complexité de structures glycanniques (Figure 2). 


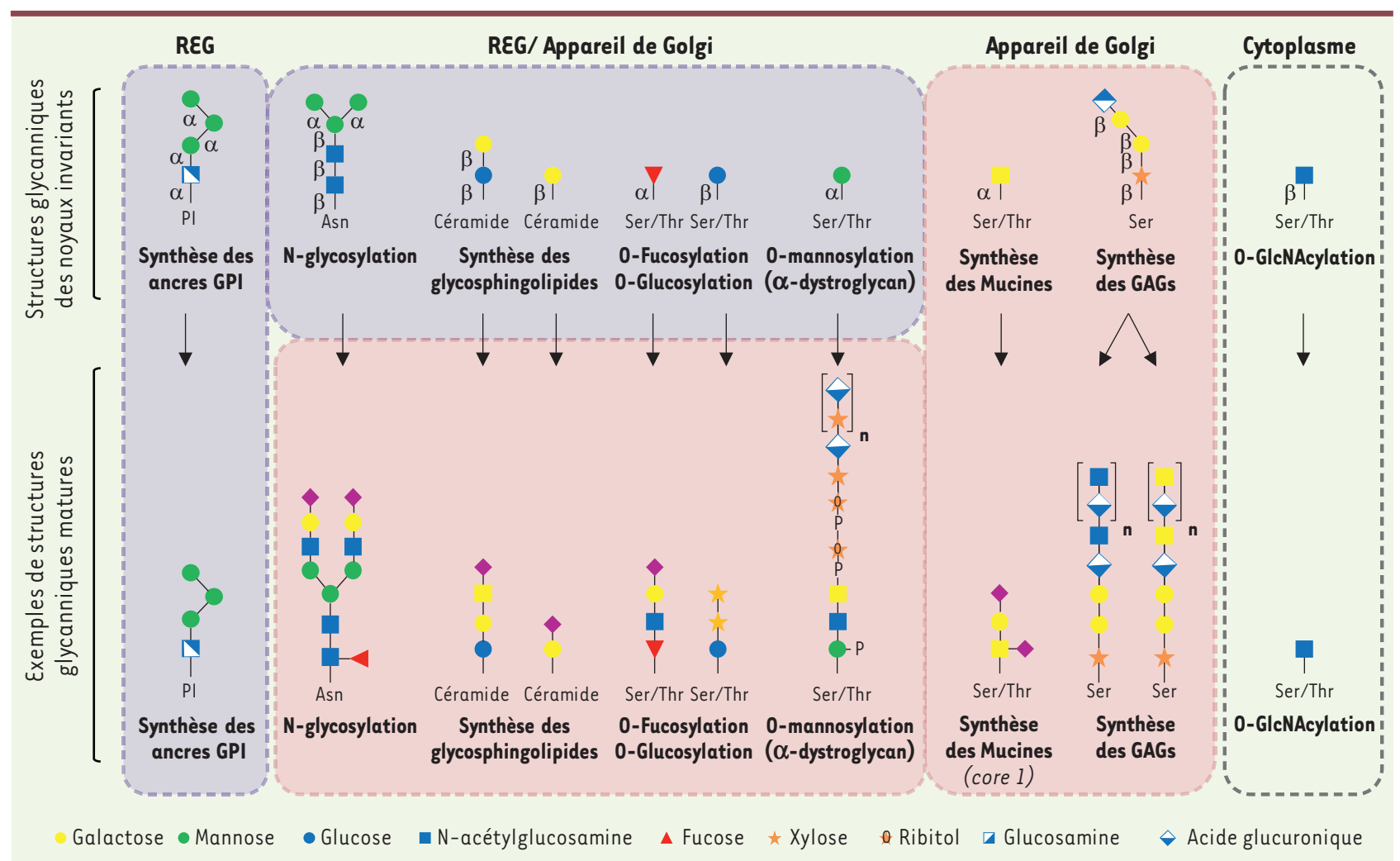

Figure 2. Représentation schématique du lieu d'initiation (noyaux invariants) et de maturation des structures glycanniques associées aux différentes voies de glycosylation. Le réticulum endoplasmique granuleux (REG) et l'appareil de Golgi sont schématiquement représentés par les encadrés en pointillé violet et rose, respectivement. À droite dans le cadre en pointillé gris, la voie de glycosylation cytoplasmique est également illustrée. La nature des différentes liaisons a été omise dans la schématisation des structures glycanniques matures par souci de lisibilité. $\alpha$ et $\beta$ représentent l'anomérie de la liaison, Asn : asparagine, GAGs: glycosaminoglycannes, GPI : glycosylphosphatidyl inositol, $n$ : nombre de répétitions du motif, P: phosphate, PI : phosphate inositol, Ser : sérine, Thr : thréonine.

Ce processus se doit donc d'être finement régulé afin d'assurer la fidélité des structures glycanniques qui seront retrouvées sur les protéines et/ou les lipides. Cette régulation est fondamentale et son altération est dramatiquement illustrée par l'existence des maladies génétiques rares et multi-systémiques, que l'on appelle anomalies congénitales de glycosylation (congenital disorders of glycosylation, $\mathrm{CDG}$ ).

De nombreux travaux ont été entrepris afin de comprendre les mécanismes de régulation de la glycosylation, dont un dysfonctionnement a également été associé à de nombreuses autres maladies acquises, telles que certains cancers, le diabète et la mucoviscidose [3,4]. Plusieurs facteurs impliqués dans cette dérégulation ont d'ores et déjà été identifiés. Certains intéressent les protéines qui sont au cœur des réactions enzymatiques: les GT, les GH, les TNS, ou l'activation et la présentation des précurseurs oligosaccharidiques principalement. D'autres sont indirectement liés à ce processus, notamment des protéines impliquées dans la localisation subcellulaire (organisation, distribution des acteurs de la glycosylation) ou le maintien de l'homéostasie de l'appareil de Golgi.

\section{Les anomalies congénitales de glycosylation}

Les CDG sont qualifiées de maladies rares. La déficience d'une des étapes du processus peut s'avérer létale pour l'embryon et les patients atteints de CDG, dits « hypomorphes $\gg^{2}$, conservent une activité résiduelle malgré les déficiences génétiques altérant différentes voies de la glycosylation.

\section{Jaak Jaeken, père des CDG}

Les premiers cas de CDG furent identifiés en 1980 par le Professeur Jaak Jaeken à l'université de Louvain en Belgique [5]. Deux sœurs jumelles monozygotes présentaient un retard psychomoteur associé à un ralentissement de la propagation de l'influx nerveux et à des anomalies de glycosylation retrouvées sur de nombreuses protéines sériques, principalement un défaut de sialylation [6]. Quinze ans plus tard, les travaux de

\footnotetext{
${ }^{2}$ Se dit d'un allèle qui réduit la fonction d'un produit génique sans l'éliminer.
} 
van Schaftingen, Matthijs et Jaeken mirent en évidence chez ces deux sœurs des mutations dans le gène PMM2, codant la phosphomannomutase 2 (PMM2), associées à un déficit de l'activité de l'enzyme et responsables des anomalies de glycosylation observées $[7,8]$. PMM2 est l'enzyme qui permet la conversion du mannose-6-phosphate en mannose-1-phosphate lors de la synthèse du GDP-mannose, un nucléotide sucre fondamental pour la synthèse du précurseur oligosaccharidique dans le REG, initiant la N-glycosylation. Le déficit en PMM2 est à l'origine d'une hypoglycosylation des protéines qui est caractéristique d'un profil CDG dit «de type I . Aujourd'hui, ce déficit reste celui dont la fréquence est la plus importante, avec plus de mille cas rapportés dans le monde.

\section{CDG et voies de glycosylation}

La majorité des cas de CDG identifiés au cours des quarante dernières années se traduit par des défauts touchant la $\mathrm{N}$-glycosylation. En 2004, Dupré et al. avaient publié une revue dans médecine/sciences qui était dédiée aux anomalies congénitales des $\rightarrow$ Voir la Synthèse de T. Dupré et al., $m / s n^{\circ} 3$, mars 2004, page 331 $\mathrm{N}$-glycosylprotéines [9] $(\rightarrow)$.

Ils y décrivaient, entre autres, les bases de la compréhension des mécanismes de la $\mathrm{N}$-glycosylation des protéines. Ce processus original s'initie dans le REG et se poursuit dans l'appareil de Golgi. Dans le $R \varepsilon G$, les principales étapes de la synthèse des $\mathrm{N}$-glycoprotéines font intervenir d'une part la synthèse d'un précurseur oligosaccharidique lipidique, de structure $G \mathrm{c}_{3} \mathrm{Man}_{9} G \mathrm{GCNAc}_{2}-\mathrm{P}$-P-dolichol ( $\mathrm{P}$, phosphate), et d'autre part, son transfert « en bloc » sur l'asparagine (Asn) de la séquence consensus Asn-X-Ser/Thr (X représentant tout acide aminé excepté Pro) portée par la protéine acceptrice. S'en suivent l'action de différentes GH impliquées dans l'acquisition du repliement correct des $\mathrm{N}$-glycoprotéines et, enfin, leurs adressages, via le trafic vésiculaire, vers l'appareil de Golgi. Les structures $\mathrm{N}$-glycanniques subissent ensuite une maturation lors du cheminement de la $\mathrm{N}$-glycoprotéine dans les différents saccules de l'appareil de Golgi. L'activité de mannosidases golgiennes est nécessaire à l'action séquentielle des GT qui conduit à la formation de structures glycanniques complexes ou hybrides (Figure 2). Outre la N-glycosylation, bon nombre de glycopathologies génétiques rares impactent d'autres - voire plusieurs - voies de glycosylation au sein d'une même cellule: la 0-glycosylation (0-fucosylation, 0-GlcNAcylation, 0-GalNAcylation, 0-glucosylation), la synthèse des glycosaminoglycanes (GAG), la synthèse des ancres glycosylphosphatidylinositol (GPI) (ou glypiation), la 0 -mannosylation de l' $\alpha$-dystroglycan et la synthèse des glycolipides [10]. Chacune de ces voies s'initie dans un compartiment cellulaire particulier, généralement le REG et/ou l'appareil de Golgi, et génère pléthore de structures glycanniques (Figure 2).

Cent-trente-trois gènes ont été associés à différents CDG [10, 11]. La Figure 3 présente un panorama du nombre de gènes mutés, de la voie de glycosylation que ces mutations affectent, et de la localisation subcellulaire des protéines codées par ces gènes et qui sont impliquées dans ces CDG. Bien que ces dernières se localisent majoritairement dans le REG et l'appareil de Golgi, certaines sont retrouvées dans le compartiment intermédiaire (ERGIC), le cytoplasme et à la membrane plasmique. Cette multiplicité des voies de glycosylation affectées participe très certainement à l'extrême diversité des phénotypes cliniques rencontrés.

\section{Quel(s) diagnostic(s) pour les CDG ?}

La plupart des CDG sont des maladies multi-systémiques et 177 phénotypes cliniques différents ont été identifiés. Ils ont été classés par organes/systèmes et chacun associé à un CDG [11]. Le diagnostic de ces pathologies est ainsi difficile et l'isoélectrofocalisation (IEF) de la transferrine sérique reste, avec la chromatographie d'échange d'ions et la spectrométrie de masse, la technique de référence pour leur dépistage. Cette méthode de séparation des protéines selon leur point isoélectrique a été à l'origine du diagnostic biochimique des premiers cas de CDG ayant pour origine des mutations du gène PMM2 en 1984 [6]. Fondée sur l'état de sialylation des deux chaînes de $\mathrm{N}$-glycannes portées par la transferrine, elle permet d'identifier et de distinguer les patients (Figure 4A). Une dérégulation de la $\mathrm{N}$-glycosylation au niveau de la synthèse et/ou du transfert du précurseur oligosaccharidique $\mathrm{Glc}_{3}$ Man${ }_{9} \mathrm{GlcNAc}_{2}$ produit en effet une sous-occupation des sites de $\mathrm{N}$-glycosylation de la protéine et caractérise un CDG de type I (CDG-I). Les profils de type I présentent ainsi une diminution des formes tétra-sialylées de la transferrine et une augmentation des formes di et/ou asialylées (Figure 4A). Une perturbation de la N-glycosylation en aval du transfert du précurseur oligosaccharidique génère en revanche l'apparition de structures N-glycanniques dites «tronquées » caractéristiques des CDG de type II (CDG-II). Dans ce cas, les deux sites de N-glycosylation sont occupés mais le nombre d'acides sialiques terminaux varie. Une augmentation globale des formes tri-, di-, mono- et/ou asialylées de la transferrine est alors évocatrice d'un profil CDG de type II (Figure 4A). La détection des glycoformes de la transferrine sérique présente néanmoins certaines limites. Elle ne permet l'identification que de patients dont le déficit touche la $\mathrm{N}$-glycosylation des protéines hépatiques. Il est donc souvent important d'examiner l'intégrité d'autres voies de glycosylation, en particulier la 0 -glycosylation. Le dépistage des anomalies de 0 -glycosylation est fondé, comme pour la transferrine, sur des méthodes de séparation de protéines comme l'IEF et/ou l'électrophorèse bidimensionnelle appliquées à I'apolipoprotéine C-III (ApoC-III) [12]. À la différence de la transferrine, I'ApoC-III n'est pas $\mathrm{N}$-glycosylée mais 0 -glycosylée. Elle comporte une unique chaîne 0 -glycannique de type mucine core $\mathrm{I}$ constituée d'une $\mathrm{N}$-acétylgalactosamine, 


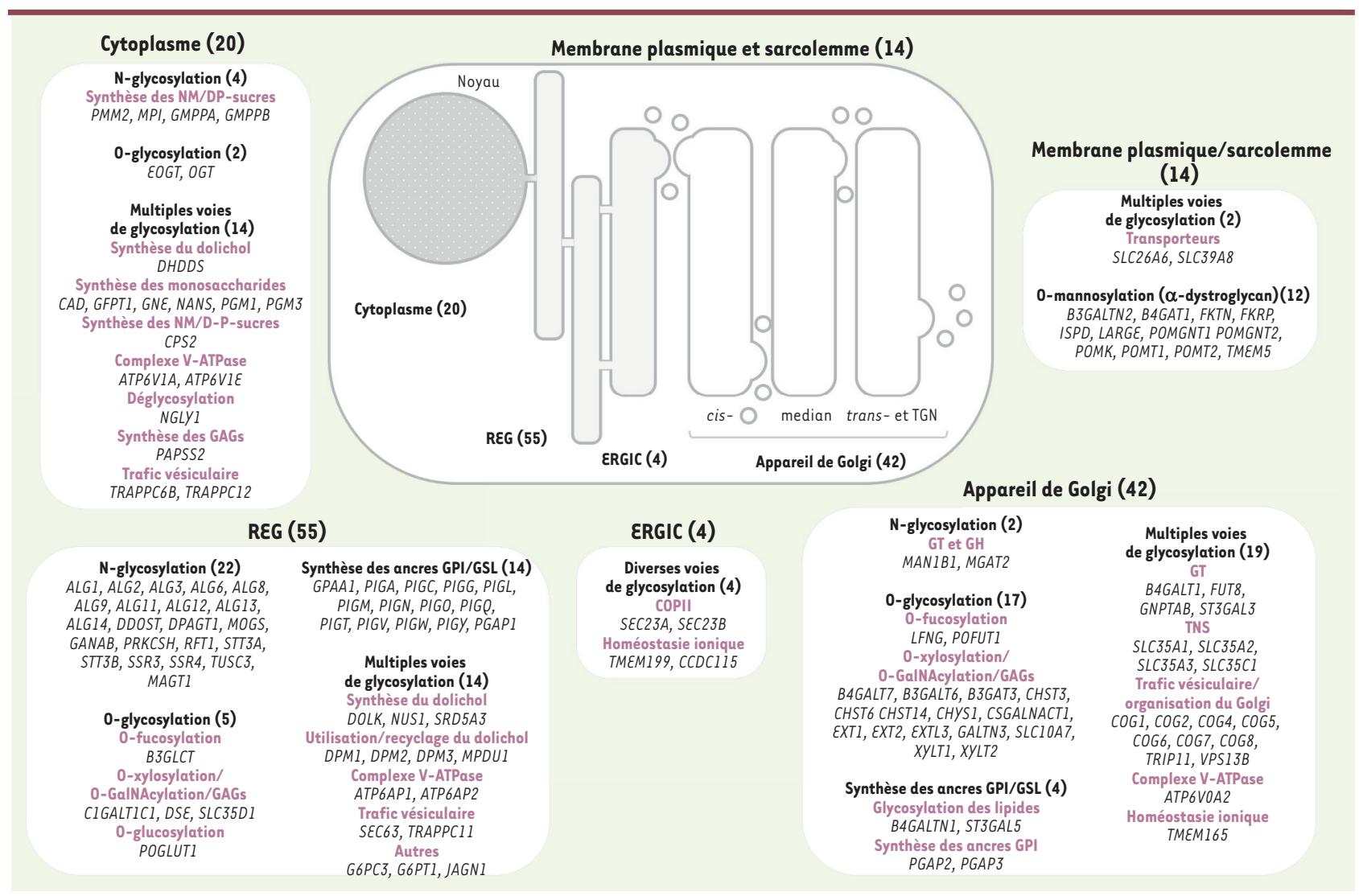

Figure 3. Panorama de la localisation subcellulaire différentielle des protéines mutées impliquées dans les anomalies congénitales de la glycosylation (congenital disorders of glycosylation [CDG]). Les différentes voies de glycosylation affectées y sont répertoriées ainsi que le gène déficient identifié. Le nombre de gènes impliqués dans chaque voie de glycosylation et associés à chaque compartiment subcellulaire, est indiqué entre parenthèses. ERGIC: endoplasmic reticulum to Golgi intermediate compartment ; NM/DP-sucres : nucléotides sucres mono/diphosphate ; REG : réticulum endoplasmique granuleux; GAG: glycosaminoglycannes; GH: glycosylhydrolases; GPI: glycosylphosphatidyl inositol ; GT : glycosyltransférases ; TGN : trans-Golgi Network; TNS : transporteur de nucléotides sucres.

d'un galactose et de deux acides sialiques (Figure 4B). Les profils de migration de la protéine résultant du nombre d'acides sialiques qu'elle porte témoignent ou non d'une anomalie de 0 -glycosylation.

Le diagnostic biochimique nécessite d'être complété par un diagnostic moléculaire afin d'identifier précisément la mutation génétique causale. Des avancées majeures ont été permises grâce à l'avènement de techniques de pointe en génomique, comme illustré par la revue de $\mathrm{Ng}$ et Freeze [10] qui montre l'intérêt du séquençage de l'exome entier (whole exome sequencing ou WES) dans le diagnostic génétique des CDG avec, entre 2010 et 2017, 51 cas identifiés (sur les 177 nouveaux cas de CDG) par cette méthode. Un arbre décisionnel pour le diagnostic a également été proposé par Francisco et al. [11].

\section{Évolution de la nomenclature des CDG}

La première tentative de classification des CDG en deux grandes familles (I et II) repose sur les résultats de profilage obtenu par IEF de la transferrine sérique (Figure $4 A$ ). Les différents CDG se distinguaient ensuite les uns des autres par une lettre, écrite en minuscule et par ordre alphabétique selon l'ordre chronologique de leur découverte.
Le CDG causé par une déficience en PMM2 fut ainsi nommé CDG-la. Suite au nombre croissant de nouveaux gènes identifiés, ce système de classification atteignit rapidement ses limites. Cette nomenclature ne permettait, aussi, que de classer les CDG déficients pour la $\mathrm{N}$-glycosylation et occultait la nature des gènes mutés [13]. Depuis 2009, un nouveau système de nomenclature a été développé prenant en compte ces deux aspects. Chaque CDG est désormais nommé par le gène déficient, écrit en capitale sans italique, accolé du suffixe «-CDG» $[14,15]$ : le CDG-la est ainsi identifié par PMM2-CDG.

\section{Une ère nouvelle pour les CDG}

Malgré le nombre important d'enzymes et de protéines impliquées dans les différentes voies de glycosylation, force est de constater qu'une grande majorité des CDG est causée par des mutations de gènes qui codent 
A

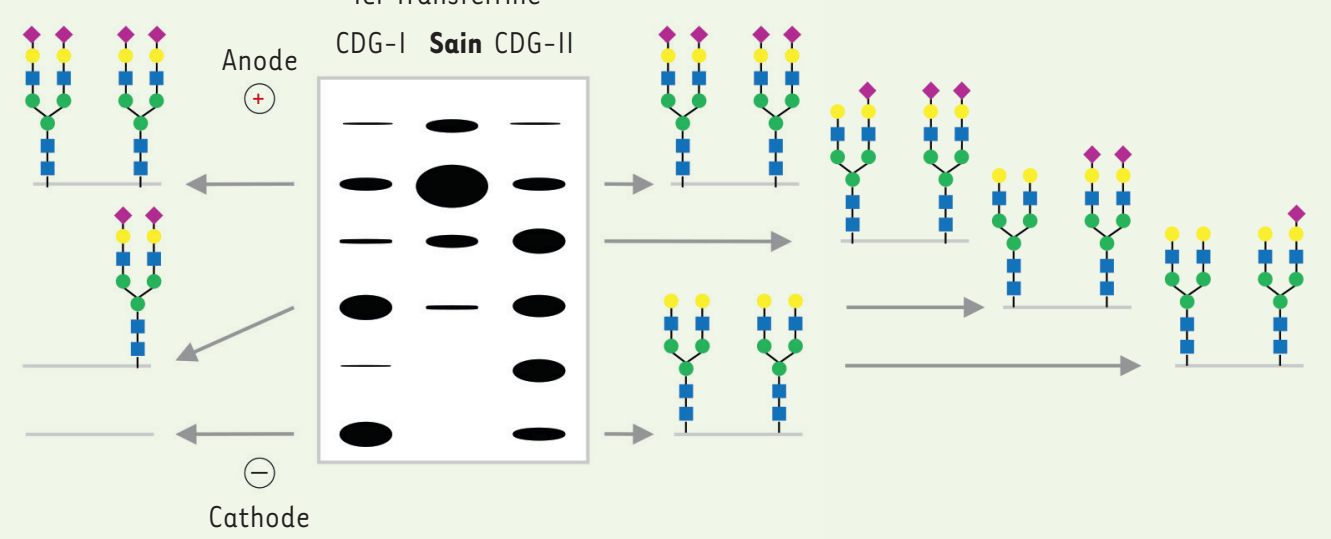

B

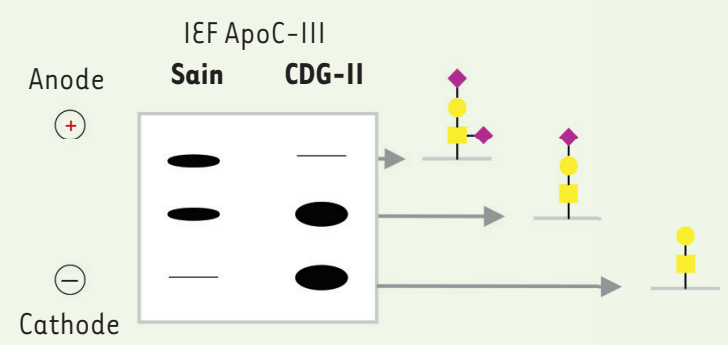

Figure 4. Illustration du diagnostic biochimique des Congenital Disorders of Glycosylation (CDG). Résultats schématiquement représentés issus de I'isoélectrofocalisation (IEF) de la transferrine (A.) et de l'apolipoprotéine-C III (ApoC-III) (B.), deux protéines sériques d'origine hépatique. Ces IEF permettent d'orienter le diagnostic biochimique des CDG. A. L'IEF de la transferrine permet l'identification d'anomalies de $\mathrm{N}$-glycosylation par le port de 2 chaînes $\mathrm{N}$-glycanniques. Selon le nombre d'acides sialiques présents et les proportions de chaque glycoforme, deux profils se distinguent reflétant un CDG-I ou un CDG-II. B. L'IEF de l'ApoC-III permet quant à elle l'identification d'anomalies de 0-glycosylation reflétées par le nombre de molécules d'acide sialique présentes sur le motif 0 -glycannique de type mucine core 1 .

des protéines participant directement aux réactions de glycosylation (GT, GH et TNS, principalement). Néanmoins, l'apparition d'un nouveau sous-groupe de patients présentant des altérations perturbant la dynamique du trafic intravésiculaire ou l'homéostasie ionique de l'appareil de Golgi, notamment celles du $\mathrm{pH}$ et du manganèse $\left(\mathrm{Mn}^{2+}\right)$ a rendu plus complexe la définition de la maladie (Figure 5). Outre l'extrême hétérogénéité des déficiences désormais identifiées, ces nouveaux phénotypes permettent de caractériser de nouveaux acteurs de la régulation du processus de glycosylation qui sont encore méconnus.

\section{CDG et trafic intravésiculaire}

\section{Importance du trafic intravésiculaire golgien}

La compartimentation cellulaire, qui permet la réalisation concomitante de nombreuses réactions biologiques, est une caractéristique fondamentale des cellules eucaryotes. Chaque organite étant délimité par une ou plusieurs bicouches lipidiques, la communication entre les compartiments ainsi que la composition et le recyclage de ces membranes, sont essentielles au maintien d'un environnement optimal (en termes de $\mathrm{pH}$, homéostasie ionique, concentration en protéines et lipides).
Cette communication repose sur un ensemble de vésicules transitant depuis le REG vers la membrane plasmique via l'appareil de Golgi (trafic antérograde) et, à l'inverse, à partir de la membrane plasmique vers le réticulum en passant par l'appareil de Golgi (trafic rétrograde).

Siège de nombreuses modifications post-traductionnelles, dont les réactions de glycosylation, l'appareil de Golgi est I'un des organites les plus dynamiques de la cellule [16]. Son organisation particulière en sous-compartiments, appelés citernes (ou saccules), requiert une distribution et une localisation correctes de tous les acteurs moléculaires nécessaires à sa fonction, en particulier aux processus de glycosylation (Figure 5). L'appareil de Golgi peut compter une douzaine de saccules polarisés (définissant 4 zones: le cis-Golgi, le médian-Golgi, le trans-Golgi et le réseau trans-Golgi [TGN]) suffisamment proches les uns des autres pour former un organite compact. II est entouré de nombreuses vésicules qui ont pour principale 


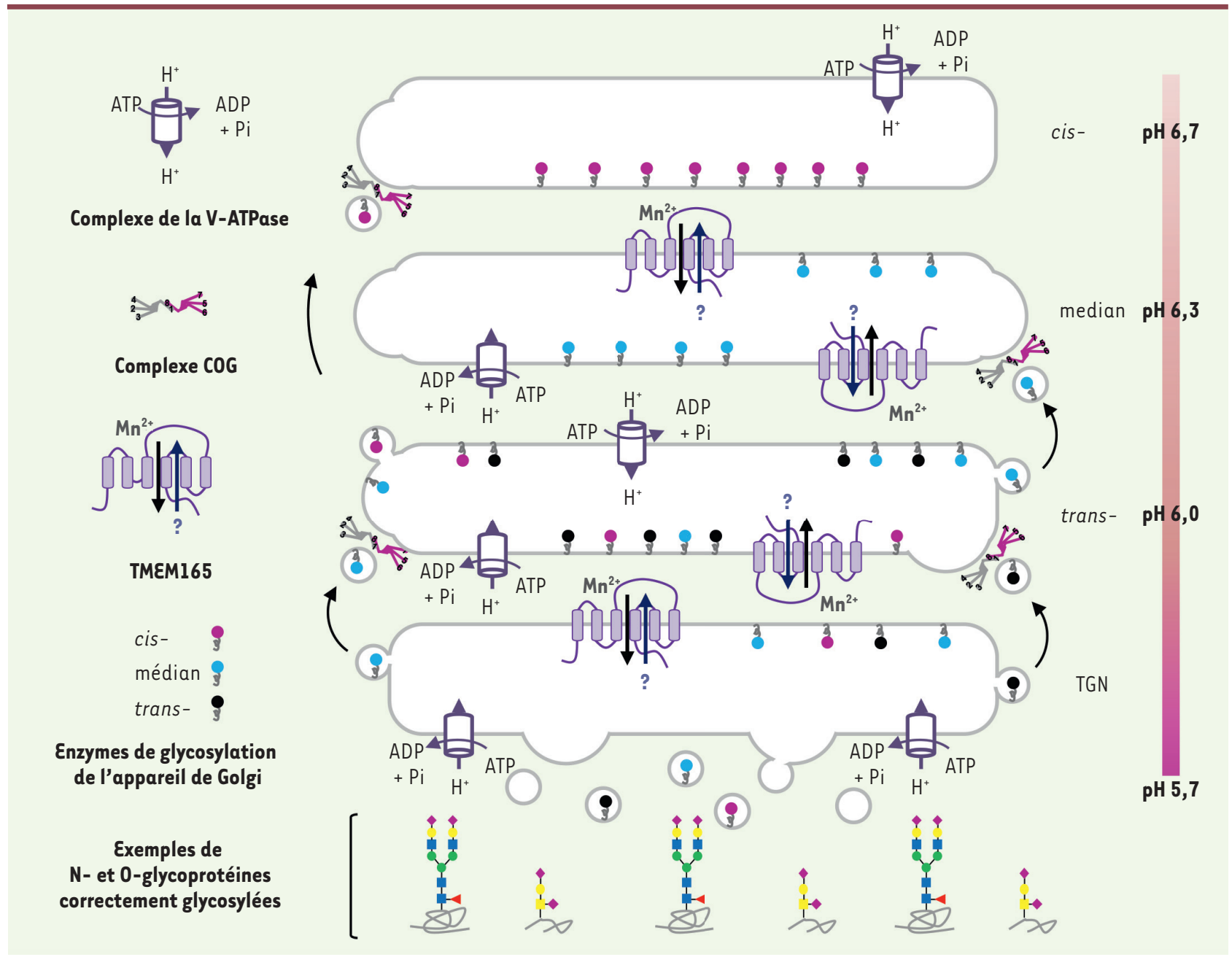

Figure 5. Représentation schématique des mécanismes cellulaires impliqués dans la régulation de la localisation subcellulaire des GT et de leurs activités. D'une part, le complexe COG assure la localisation correcte des GT via le trafic rétrograde. D'autre part, la V-ATPase et TMEMI65 régulent les homéostasies du pH et du $\mathrm{Mn}^{2+}$ de l'appareil de Golgi, requises pour l'activité de ces GT. L'ensemble de ces mécanismes est essentiel à la génération de structures glycanniques matures correctes. Tout dysfonctionnement de ces mécanismes engendre un CDG. Le point d'interrogation représente un ion dont la nature reste à spécifier. COG : Conserved Oligomeric Golgi, TMEM165: Transmembrane protein 165, TGN : Trans-Golgi Network.

fonction d'acheminer et de recycler des enzymes dans des citernes spécifiques. La dynamique de ce compartiment est telle que la moindre faille dans la formation, l'adressage et la fusion des vésicules a des conséquences désastreuses.

Au cours de la dernière décennie, les travaux portant sur les protéines du complexe COG (conserved oligomeric golgi) ont révélé son rôle essentiel dans le trafic rétrograde intravésiculaire golgien, et son implication dans la glycosylation golgienne. Le complexe COG est constitué de huit sous-unités, COGl à COG8, réparties en deux lobes distincts : le lobe $A$ formé des sous-unités COGl à 4 , et le lobe $B$ qui comprend les sous-unités COG5 à 8. Ces deux lobes sont associés par une interaction établie entre les sous-unités COGl du lobe $A$ et COG8 du lobe B. Chaque sous-unité du complexe peut interagir avec différentes protéines qui participent au trafic intravésiculaire, telles que les SNARE (soluble
$N$-ethylmaleimide-sensitive-factor attachment protein receptor) et les GTPase Rab, les protéines de fusion et d'adressage des vésicules [17].

\section{Perturbation du trafic intravésiculaire golgien et CDG}

L'importance du complexe COG dans l'adressage et le recyclage des enzymes de glycosylation golgiennes a été révélée par la mise en évidence de déficits de l'une des sous-unités du complexe chez des patients souffrant de CDG-II. Les premier cas, découverts en 2004, impliquaient COG7 [18]. II s'agissait d'un frère et d'une sœur, présentant les symptômes cliniques d'un CDG (une hypotonie, une asphyxie périnatale et une dysmorphie - oreilles basses, peau lâche et ridée). Ils sont 
décédés respectivement après cinq et dix semaines de vie des suites d'infections répétées et d'insuffisance cardiaque. Les profils d'IદF de la transferrine et d'Apoc-III étaient anormaux et une diminution de l'activité de deux GT, impliquées dans l'élongation des structures $\mathrm{N}$ - et 0 -glycanniques, a été observée. Un lien entre intégrité du trafic intravésiculaire golgien (révélé par le déficit en $\mathrm{COG} 7$ ) et le processus de glycosylation fut dès lors établi. De nombreuses mutations affectant sept des huit sous-unités constitutives du complexe COG (COG3 étant l'exception) ont par la suite été identifiées [19-25]. Environ un tiers des patients atteints de CDG-II présentent de telles mutations. Les mécanismes par lesquels sont générés les défauts de glycosylation ont fait l'objet de nombreuses études et ont partiellement été élucidés. Certaines déficiences perturbent notamment la structure même de l'appareil de Golgi et le trafic rétrograde intra-golgien de vésicules contenant des protéines importantes pour les réactions de glycosylation, telles que les GT et/ou les transporteurs de nucléotides sucres (TNS). Plus qu'une localisation golgienne anormale, les derniers travaux montrent une instabilité de certaines GT, résultant d'un adressage lysosomal inadéquat, en particulier MGAT (GLCNAc transférases 1 et 2), MAN2Al ( $\alpha$-mannosidase class $2 A$ member 1 ), B4GALT1 ( $\beta$-1,4-galactosyltransferase 1 ) et ST6GALl ( $\beta$-galactoside alpha-2,6-sialyltransferase 1) [26, 27]. L'altération du complexe COG est donc à l'origine de la déplétion d'acteurs clefs de la glycosylation golgienne provoquant les défauts de $\mathrm{N}$ - et 0 -glycosylation observés chez tous les patients COG-CDG.

\section{CDG et pH de l'appareil de Golgi}

\section{Régulation du pH de l'appareil de Golgi}

La régulation du $\mathrm{pH}$ de l'appareil de Golgi repose principalement sur l'activité de trois familles de protéines: les ATPases vacuolaires, encore appelées ATPases de type V (V-ATPase), qui importent des protons du cytoplasme vers la lumière de l'appareil de Golgi ; les canaux de fuite à protons, permettant d'ajuster finement le $\mathrm{pH}$; et les canaux ioniques qui assurent l'influx d'anions ou l'efflux de cations pour maintenir le potentiel membranaire $[28,29]$. Nous ne présenterons que les V-ATPase dont les altérations ont été révélées chez des patients CDG.

Les V-ATPase se composent d'un domaine cytoplasmique $V_{1}$ et d'un domaine transmembranaire $V_{0}$, chacun de ces domaines étant luimême constitué de plusieurs sous-unités. Leur rôle dans l'acidification des organites de la voie de sécrétion a été démontré par l'utilisation d'inhibiteurs spécifiques, tels que la bafilomycine Al et la concanamycine $A$, qui conduit à une alcalinisation des compartiments acides de la cellule et de l'appareil de Golgi [30].

\section{Perturbation du pH de l'appareil de Golgi et CDG}

Plusieurs mutations touchant différentes sous-unités de la V-ATPase sont responsables de CDG-II [31], révélant ainsi l'importance de la régulation du $\mathrm{pH}$ de l'appareil de Golgi dans le processus de glycosylation (Figure 5). Ainsi, des mutations du gène ATP6VOA2 codant la sous-unité a2 du domaine $V_{0}$ de la V-ATPase, découvertes en 2008 par Kornak et al. [32] affectent la fonctionnalité de la protéine avec une alcalinisa- tion de l'appareil de Golgi qui conduit à l'apparition de structures $\mathrm{N}$ - et $\mathrm{O}$-glycanniques anormales, principalement asialylées et agalactosylées. Le mécanisme par lequel cette alcalinisation perturbe la glycosylation n'est pas complétement élucidé. Deux hypothèses peuvent toutefois être proposées. Cette augmentation de $\mathrm{pH}$ affecterait soit directement l'activité des enzymes de la glycosylation, en particulier les sialyltransférases, soit le trafic intracellulaire golgien, générant une mauvaise localisation subcellulaire de ces enzymes [29, 33, 34].

D'autres mutations responsables de CDG-II ont récemment été identifiées dans les gènes ATP6VIA et ATP6VIEl qui codent respectivement les sous-unités $A$ et $\varepsilon l \mathrm{du}$ domaine $V_{1}$ de la V-ATPase [35] mais également des mutations de gènes codant des protéines accessoires de la V-ATPase, comme ATP6AP1 et ATP6AP2, ou encore TMEM199 (transmembrane protein 199) et CCDC115 (coiled-coil domain containing 115). TMEM199 et CCDC115 sont les orthologues humains de deux protéines de levure, Vma12p et Vma22p, qui, avec Vma2lp, constitue un complexe qui « chaperonne » l'assemblage du domaine $V_{0}$ de la V-ATPase au niveau du REG [36, 37]. Le phénotype clinique des patients est assez particulier, avec notamment des niveaux de transaminases sériques chroniquement élevés et un taux de céruloplasmine sérique faible. Curieusement, le métabolisme du cuivre est également altéré chez ces patients. Le lien entre $\mathrm{pH}$ du Golgi, anomalies de la glycosylation et perturbation du métabolisme du cuivre reste à explorer.

\section{CDG et homéostasie golgienne}

de l'ion manganèse $\left(\mathrm{Mn}^{2+}\right)$

\section{Régulation de l'homéostasie golgienne du $\mathbf{M n}^{2+}$}

Le manganèse $(\mathrm{Mn})$ est un élément trace, essentiel à la réalisation de nombreux processus cellulaires physiologiques. Chez l'homme, la quantité totale de $\mathrm{Mn}$, dont les formes biologiquement actives sont les ions $\mathrm{Mn}^{2+}$ et $\mathrm{Mn}^{3+}$, est comprise entre 10 et $20 \mathrm{mg}$. Son homéostasie est principalement régulée par la balance absorption/excrétion. Les effets néfastes de l'accumulation du Mn dans l'organisme sont bien documentés. Inhalé à forte dose via des expositions répétées, il est neurotoxique, conduisant à un trouble neurologique appelé «manganisme » similaire à la maladie de Parkinson [38]. Cependant, aucun cas de carence en Mn n'avait été rapporté.

\section{Perturbation de l'homéostasie du $\mathrm{Mn}^{2+}$ et CDG}

En 2012, notre équipe a montré qu'une carence en $\mathrm{Mn}$ au niveau de l'appareil de Golgi, reposant sur un déficit en TMEM165, provoquait un CDG-II [39-41]. Par l'étude de la fonction de TMEMI65 et de son orthologue chez la 
levure Saccharomyces cerevisiae, Gdtlp [42-44], ces travaux ont permis d'établir un lien entre homéostasie golgienne $\mathrm{du} \mathrm{Mn}^{2+}$ et processus de glycosylation. TMEM165 est en effet un acteur majeur de la régulation de I'homéostasie du $\mathrm{Mn}^{2+}$ en permettant son import dans l'appareil de Golgi (Figure 5). À ce niveau, le $\mathrm{Mn}^{2+}$ est un cofacteur de nombreuses glycosyltransférases, qui, en s'associant au site catalytique, les rend actives. La déficience en TMEM165 induirait une diminution de la concentration de $\mathrm{Mn}^{2+}$ au niveau de la lumière de l'appareil de Golgi et affecterait principalement le transfert sur les glycoconjugés, des NDP-sucres, en particulier I'UDP-galactose et I'UDP-GalNAc. Chez les patients déficients en TMEM165, toutes les voies de glycosylation sont donc affectées, ce qui participe très certainement aux anomalies osseuses sévères observées. In vitro, le déficit de $\mathrm{Mn}^{2+}$ dans les cellules déficientes en TMEMI65 peut être comblé par un apport exogène en $\mathrm{Mn}^{2+}$ qui permet la correction des défauts de glycosylation observés dans ces cellules [45-47]. Le mécanisme de cette restauration reste cependant encore incompris mais l'importance du REG, en particulier des pompes SERCA (sarco endoplasmic reticulum $\left(a^{2+}\right.$-ATPase) a été suggéré : en l'absence de TMEM165, ce mécanisme permettrait de fournir en ions $\mathrm{Mn}^{2+}$ via le REG, l'appareil de Golgi [47].

Récemment, un autre CDG-II affectant l'homéostasie cellulaire du Mn a été rapporté. II s'agit du SLC39A8-CDG, identifié en 2015 par Park et al. [48]. Contrairement à TMEM165 qui est localisé au niveau de l'appareil de Golgi, SLC39A8 est un transporteur de cations divalents situé à la membrane plasmique. II permet l'import des ions $\mathrm{Mn}^{2+}$ et zinc $\left(\mathrm{Zn}^{2+}\right)$ dans le cytoplasme. Comme chez les patients TMEM165-CDG, une hypogalactosylation massive des structures glycanniques associée à un phénotype clinique osseux sévère sont observés chez les patients SLC39A8-CDG.

\section{Quels traitements pour les CDG ?}

Les résultats issus de la recherche combinés aux données cliniques permettent une meilleure compréhension des mécanismes à l'origine des défauts de glycosylation et permettent d'envisager, pour certains patients CDG, de possibles traitements. Néanmoins, aucun traitement ne permet aujourd'hui de corriger les atteintes sévères, en particulier neurologiques et osseuses, qui apparaissent chez ces patients au cours de leur développement. Nous examinerons les principales avancées et stratégies thérapeutiques actuelles ciblant les CDG [49].

\section{Administration orale de monosaccharides et ions}

Certains CDG résultent d'un déficit de protéines directement impliquées dans la synthèse ou le transport des nucléotides sucres. Dans certains cas, des traitements relativement simples à mettre en œuvre sont envisageables. Ils consistent en l'apport exogène du monosaccharide/ion par I'alimentation. Cette stratégie présente l'avantage d'être relativement inoffensive pour les patients et peu onéreuse. Selon le CDG considéré, une administration orale de monosaccharide peut-être combinée à celle d'éléments traces, tels que les ions $\mathrm{Mn}^{2+}$. À l'heure actuelle, cette approche thérapeutique cible une dizaine de CDG et de nombreuses revues rendent compte des différents traitements établis [49-53], dont certains sont présentés ici.

\section{Le D-mannose}

Le D-mannose est un monosaccharide qui participe à plusieurs voies de glycosylation, dont la N-glycosylation, la 0 -glycosylation, la C-mannosylation et la synthèse des ancres GPI. Le premier cas de CDG ayant bénéficié de ce traitement fut un patient atteint de MPI (mannose phosphate isomérase)-CDG. L'apport exogène de $D$-mannose compense dans ce cas le déficit en mannose phosphate isomérase, l'enzyme responsable de la conversion du fructose-6-phosphate en mannose-6-phosphate. Ce mannose exogène est converti en mannose-6-phosphate par l'hexokinase. II est ensuite activé en GDP-mannose afin d'être utilisé par les GT. L'administration par voie orale de D-mannose ( $1 \mathrm{~g} / \mathrm{kg}$ par jour en trois à quatre prises), tend à normaliser le profil des glycoformes de la transferrine sérique. Elle améliore considérablement les fonctions endocriniennes et les facteurs de coagulation chez les patients traités [51]. La posologie du D-mannose doit cependant être finement ajustée en raison d'effets secondaires gastro-intestinaux et hématologiques. Ce traitement ne s'applique que pour le MPI-CDG, et non pour le PMM2 (phosphomannomutase 2)-CDG, dont la déficience affecte la conversion du mannose-6-phosphate en mannose-1-phosphate. Le traitement chez les patients souffrant de PMM2-CDG ne conduirait qu'à une augmentation de mannose-6-phosphate et non à celle de mannose-1-phosphate, produit par la PMM2. Une stratégie pharmacologique d'encapsulation du mannose-1-phosphate dans des liposomes, élaborée par la société Glycomine, a été entreprise pour ces patients. Cette approche prometteuse permettrait de délivrer directement le nucléotide sucre manquant aux cellules. Les premiers essais cliniques devraient débuter prochainement.

\section{Le L-fucose}

Le L-fucose est un monosaccharide retrouvé dans différentes structures $\mathrm{N}$ - et $\mathrm{O}$-glycanniques ainsi que dans les glycolipides. L'import de GDP-fucose dans l'appareil de Golgi se réalise principalement grâce au transporteur $\mathrm{SLC35Cl}$ (solute carrier family 35 member $\mathrm{Cl}$ ). Chez les patients présentant un SLC35Cl-CDG, l'apport exogène de L-fucose tend à normaliser le défaut de glycosylation. Le mécanisme de cette normalisation n'est pas complètement élucidé, mais il reposerait sur une augmentation de la concentration cellulaire de GDPfucose, permettant ainsi son import dans l'appareil de Golgi malgré l'altération de son tranporteur SLC35Cl. Chez ces patients, principalement immunodéficients, ce traitement diminue les infections et normalise le nombre de leucocytes circulants [51]. 


\section{Le D-galactose}

L'import d'UDP-galactose dans l'appareil de Golgi repose sur l'activité du transporteur SLC35A2 (solute carrier family 35 member A2). Un défaut de galactosylation des structures $\mathrm{N}$ - et 0 -glycanniques, ainsi que de certains glycolipides, est observé chez certains patients CDG. Ces défauts ont des origines multiples et résultent soit d'une moindre quantité d'UDP-galactose (pour les PGMI[phosphoglucomutase 1]-CDG), soit d'un défaut d'import d'UDP-galactose dans l'appareil de Golgi (pour les SLC35A2-CDG), soit, enfin, d'une altération enzymatique de son transfert sur les structures glycanniques (pour les SLC39A8-CDG et les TMEMI65CDG). Le défaut de galactosylation chez ces patients est corrigé par l'administration orale de D-galactose (entre 0,5 et $1,5 \mathrm{~g} / \mathrm{kg}$ par jour) $[45,49,51]$. Les mécanismes de la restauration sont néanmoins complexes et diffèrent selon le déficit. Une conséquence constante faisant suite à l'apport exogène de D-galactose est néanmoins l'augmentation du pool cytoplasmique d'UDP-galactose. Dans le cas du SLC35A2-CDG, le mécanisme reste incompris mais impliquerait vraisemblablement l'activité d'un autre transporteur golgien dans l'import d'UDP-galactose. Pour le PGM1-CDG où la conversion du glucose-6-phosphate en glucose1-phosphate est altérée, l'apport exogène de D-galactose favoriserait à la fois la production d'UDP-galactose et d'UDP-glucose par l'action de I'UDP-galactose 4-épimérase (GALE).

\section{Le D-galactose et l'ion $\mathrm{Mn}^{2+}$}

Dans les cas particuliers de SLC39A8-CDG et TMEMI65-CDG, un apport exogène combiné de $\mathrm{D}$-galactose et d'ion $\mathrm{Mn}^{2+}$ (sous la forme de $\mathrm{MnCl}_{2}$ ou de $\mathrm{MnSO}_{4}$ ) semble être un traitement de choix. L'UDP-galactose et les ions $\mathrm{Mn}^{2+}$ étant les substrats et cofacteurs de la $\beta$ - 1,4galactosyltransférase (B4GALT1), leur apport exogène permettrait de stimuler son activité afin d'accroître le transfert de galactose sur les structures glycanniques. Dans le cas du SLC39A8-CDG, cette combinaison a donné des résultats prometteurs avec une normalisation des défauts de glycosylation, associée à l'amélioration de nombreux paramètres biochimiques $[48,54]$. Le principal inconvénient dans la mise en place d'un tel traitement repose sur la toxicité du Mn. II doit donc s'accompagner du contrôle de nombreux paramètres afin de prévenir ces effets toxiques sur l'organisme. Pour la déficience en TMEM165, des études in vitro menées sur des lignées de cellules HعK293 dans lesquelles le gène TMEM165 a été invalidé, ont d'ores et déjà prouvé l'effet bénéfique d'une supplémentation en $D$-galactose et en ions $\mathrm{Mn}^{2+}$ sur la restauration des profils de glycosylation des structures $\mathrm{N}$-glycanniques et des glycolipides produits par les cellules $[45,47]$. Des essais cliniques utilisant cette combinaison sont actuellement en cours de validation sur deux patients TMEMI65-CDG.

\section{Transplantations}

Les CDG se caractérisent par une atteinte multi-systémique [11] et dans $22 \%$ des cas, le foie des patients est atteint, ce qui se traduit par une cirrhose, une insuffisance hépatique ou, dans les cas les plus sévères, une fibrose hépatique. C'est le cas, avec différents degrés de gravité, des patients TMEM199-CDG, CCDC115-CDG, ATPAP1-CDG, MPI-CDG, PMM2-CDG et PGM1-CDG [49]. Dans les cas de PMM2- et
PGMI-CDG, les taux élevés de transaminases associés à une stéatose confirment le dysfonctionnement du foie. Néanmoins, la question d'une transplantation de foie est délicate, puisque les taux de transaminases peuvent se normaliser au cours du temps (pour les PMM2-CDG) ou après un traitement au D-galactose (pour les PGMICDG). En revanche, dans le cas d'une fibrose hépatique avancée, que l'on observe principalement chez les patients MPI-CDG, la transplantation est le seul moyen de rétablir une fonction hépatique. Ces transplantations ont été réalisées avec succès chez plusieurs patients MPI-, ATP6API - et CCDC115-CDG.

Le foie n'est malheureusement pas le seul organe sévèrement atteint chez certains patients. Pour les patients DOLK (dolichol kinase)-CDG, des atteintes cardiaques ont été rapportées et deux transplantations de cœur ont été réalisées avec succès. Dans les cas d'immunodéficiences sévères telles qu'on les observe chez les patients PGM3 (phosphoglucomutase 3)-CDG, une transplantation de cellules souches hématopoïétiques s'est avérée être bénéfique en diminuant les troubles immunitaires [49].

\section{Utilisation des chaperonnes pharmacologiques et de l'acétazolamide}

Les chaperonnes pharmacologiques (CP) sont de petites molécules pouvant lier les protéines mutées mal conformées et les stabiliser et, ainsi, empêcher leur dégradation prématurée. Dans le cas du PMM2-CDG, près de $80 \%$ des patients portent la mutation fauxsens $\mathrm{p} . \mathrm{R} 14 \mathrm{lH}$ responsable du déficit enzymatique de la PMM2. Après le criblage haut débit de 10000 molécules pharmacologiques, Yuste-Checa et al. [55] ont sélectionné quatre composés susceptibles de jouer le rôle de CP pour la PMM2. Ces composés, en stabilisant la protéine mutée, empêchent sa dégradation et favorisent le maintien de sa fonctionnalité, bien qu'elle soit altérée. Chez les patients PMM2-CDG, des accidents vasculaires cérébraux (ou stroke like episodes, SLE) apparaissent. Ces SLE sont également observés dans d'autres types de maladies neurologiques, dont les migraines hémiplégiques familiales (MHF). L'acétazolamide (ou AZATAX) est un traitement de choix pour ces MHF. II réduit considérablement la fréquence de ces épisodes cérébraux. Dans le cadre du déficit de PMM2, I'AZATAX a été testé sur une cohorte de patients. Bien toléré, son administration a produit des résultats spectaculaires chez certains d'entre eux avec, notamment, une amélioration des syndromes cérébelleux moteurs. Là encore, le mécanisme d'action de l'acétazolamide reste incompris même si l'on suppose qu'il est impliqué dans la régulation d'un transporteur de calcium [56]. 


\section{Conclusion}

II y a 60 ans, face aux découvertes majeures qui concernaient l'ADN et I'ARN, la glycobiologie représentait un domaine d'étude anecdotique. Mais, depuis la détection de glycopathologies génétiques rares chez l'homme, une prise de conscience de l'importance des réactions de glycosylation et de leur régulation dans la communauté scientifique a propulsé ce domaine de recherche au tout premier plan. L'identification et la caractérisation de nouveaux CDG ont révélé des partenaires insoupçonnés de la régulation du processus de glycosylation et ont dévoilé leur importance dans d'autres voies métaboliques.Au-delà d'offrir un panorama des CDG sur les 40 dernières années, nous avons tenté de présenter les bases de cette science, la glycobiologie. Nous souhaitons que ces quelques lignes aient attisé la curiosité du lecteur en l'invitant à en découvrir davantage sur le vaste domaine des glycosciences. $\diamond$

\section{SUMMARY}

Panorama on congenital disorders of glycosylation (CDG): from 1980 to 2020

Glycosylation is an essential and complex cellular process where monosaccharides are added one by one onto an acceptor molecule, most of the time a protein or a lipid, so called glycoprotein or glycolipid. This cellular process is found in every living organism and is tightly conserved during evolution. In human, if one of the glycosylation reactions is genetically impaired, Congenital Disorders of Glycosylation (CDG) appear. CDG are a growing family of more than a hundred genetic diseases. This review offers a panorama of CDGs from 1980 to the present, their discoveries, diagnoses and treatments. $\diamond$

Marine Houdou a été lauréate du prix des Journées André Verbert 2019, École doctorale Biologie-Santé de l'université de Lille.

\section{LIENS D'INTÉRÊT}

Les auteurs déclarent n'avoir aucun lien d'intérêt concernant les données publiées dans cet article.

\section{RÉFÉRENCES}

1. Ramakrishnan B, Ramasamy V, Pasba PK. Structural snapshots of $\beta$-1,4-galactosyltransferase-I along the kinetic pathway. J Mol Biol 2006 ; 357 : 1619-33.

2. Hadley B, Litfin T, Day CJ, et al. Nucleotide sugar transporter SLC35 family structure and function. Comput Struct Biotechnol ) 2019 ; 17 : 1123-34.

3. Brockhausen I, Schutzbach J, Kuhns W. Glycoproteins and their relationship to human disease. Cells Tissues Organs $1998 ; 161: 36-78$.

4. Schachter H, Freeze HH. Glycosylation diseases: Quo vadis? Biochim Biophys Acta 2009 ; 1792 : 925-30.

5. Jaeken J, Vanderschueren-Lodeweyckx M, Casaer P. Familial psychomotor retardation with markedly fluctuating serum prolactin, FSH and GH levels, partial TGB-deficiency, increased serum arylsulphatase A and increased CSF protein: a new syndrome? Pediatr Res 1980 ; 14, 179.

6. Jaeken J, Eijk HG van, Heul C van der, et al. Sialic acid-deficient serum and cerebrospinal fluid transferrin in a newly recognized genetic syndrome. Clin Chim Acta 1984 ; $144: 245-47$.

7. Van Schaftingen $\varepsilon$, Jaeken J. Phosphomannomutase deficiency is a cause of carbohydratedeficient glycoprotein syndrome type I. FEBS Lett $1995 ; 377$ : 318-20.

8. Matthijs G, Schollen $\varepsilon$, Pardon $\varepsilon$, et al. Mutations in PMM2, a phosphomannomutase gene on chromosome $16 \mathrm{p} 13$, in carbohydrate-deficient glycoprotein type I syndrome (Jaeken syndrome). Nat Genet $1997 ; 16: 88-92$.

9. Dupré $T$, Lavieu $G$, Moore $\mathrm{S}$, et al. Les anomalies congénitales de glycosylation des N-glycosylprotéines. Med/Sci (Paris) $2004 ; 20: 331-8$.

10. Ng BG, Freeze HH. Perspectives on glycosylation and its congenital disorders. Trends Genet 2018 ; $34: 466-76$.
11. Francisco R, Marques-da-Silva D, Brasil S, et al. The challenge of CDG diagnosis. Mol Genet Metab 2019 ; 126 : 1-5.

12. Wopereis S. Apolipoprotein C-III isofocusing in the diagnosis of genetic defects in 0-glycan biosynthesis. Clin Chem 2003 ; 49 : 1839-45.

13. Jaeken J, Hennet T, Freeze $\mathrm{HH}$, et al. On the nomenclature of congenital disorders of glycosylation (CDG).J Inherit Metab Dis. 2008 ; 31 : 669-72.

14. Jaeken J, Hennet T, Matthijs G, et al. CDG nomenclature: time for a change! Biochim Biophys Acta 2009 ; 1792 : 825-6.

15. Jaeken J. Congenital disorders of glycosylation (CDG): it's (nearly) all in it! J Inherit Metab Dis 2011 ; 34 : 853-58.

16. Potelle S, Klein A, Foulquier F. Golgi post-translational modifications and associated diseases. J Inherit Metab Dis 2015 ; 38 : 741-51.

17. Willett R, Ungar D, Lupashin V. The Golgi puppet master: COG complex at center stage of membrane trafficking interactions. Histochem Cell Biol $2013 ; 140: 271-83$

18. Wu X, Steet RA, Bohorov 0, et al. Mutation of the COG complex subunit gene COG7 causes a lethal congenital disorder. Nat Med $2004 ; 10: 518-23$.

19. Foulquier F, Vasile $\varepsilon$, Schollen $\varepsilon$, et al. Conserved oligomeric Golgi complex subunit 1 deficiency reveals a previously uncharacterized congenital disorder of glycosylation type II. Proc Natl Acad Sci USA 2006 ; 03 : 3764-69.

20. Foulquier $F$, Ungar $D$, Reynders $\varepsilon$, et al. A new inborn error of glycosylation due to a $\operatorname{Cog} 8$ deficiency reveals a critical role for the $\operatorname{Cog} 1-\operatorname{Cog} 8$ interaction in COG complex formation. Hum Mol Genet 2007 ; 16 : 717-30.

21. Kranz C, Ng BG, Sun L, et al. COG8 deficiency causes new congenital disorder of glycosylation type Ilh. Hum Mol Genet 2007 ; 16 : 731-41.

22. Reynders $\varepsilon$, Foulquier $F$, Leão Teles $\varepsilon$, et al. Golgi function and dysfunction in the first COG4-deficient CDG type II patient. Hum Mol Genet 2009 ; 18 : 3244-56.

23. Paesold-Burda P, Maag C, Troxler H, et al. Deficiency in COG5 causes a moderate form of congenital disorders of glycosylation. Hum Mol Genet $2009 ; 18: 4350-6$.

24. Lubbehusen J, Thiel C, Rind N, et al. Fatal outcome due to deficiency of subunit 6 of the conserved oligomeric Golgi complex leading to a new type of congenital disorders of glycosylation. Hum Mol Genet 2010 ; 19 : 3623-33.

25. Kodera $\mathrm{H}$, Ando $\mathrm{N}$, Yuasa I, et al. Mutations in COG2 encoding a subunit of the conserved oligomeric golgi complex cause a congenital disorder of glycosylation: COG2 mutations cause congenital disorder of glycosylation. Clin Genet $2015 ; 87: 455-60$.

26. Pokrovskaya ID, Willett R, Smith RD, et al. Conserved oligomeric Golgi complex specifically regulates the maintenance of Golgi glycosylation machinery. Glycobiology $2011 ; 21: 1554-69$.

27. Shestakova A, Zolov S, Lupashin V. COG complex-mediated recycling of Golgi glycosyltransferases is essential for normal protein glycosylation: COG complex and Golgi glycosylation. Traffic 2006 ; 7 : 191-204

28. Kellokumpu S. Golgi pH, ion and redox homeostasis: how much do they really matter? Front Cell Dev Biol $2019 ; 7: 93$

29. Rivinoja A, Hassinen A, Kokkonen $\mathrm{N}$, et al. Elevated Golgi pH impairs termina $\mathrm{N}$-glycosylation by inducing mislocalization of Golgi glycosyltransferases. J Cell Physiol $2009 ; 220$ : 144-54.

30. Rivinoja A, Pujol FM, Hassinen A, et al. Golgi pH, its regulation and roles in human disease. Ann Med 2012 ; 44 : 542-54.

31. Guillard M, Dimopoulou A, Fischer B, et al. Vacuolar $\mathrm{H}^{+}$-ATPase meets glycosylation in patients with cutis laxa. Biochim Biophys Acta $2009 ; 1792$ : 903-14.

32. Kornak U, Reynders $\varepsilon$, Dimopoulou A, et al. Impaired glycosylation and cutis laxa caused by mutations in the vesicular $\mathrm{H}^{+}$-ATPase subunit ATP6VOA2. Nat Genet $2008 ; 40: 32-4$

33. Maeda Y. pH control in Golgi apparatus and congenital disorders of glycosylation. In : Taniguchi N, Endo T, Hart GW, et al., eds. Glycoscience: biology and medicine. Tokyo: Springer Japan, 2015 : 921-25.

34. Maeda Y, Kinoshita T. The acidic environment of the Golgi is critical for glycosylation and transport. Methods enzymology. Amsterdam : Elsevier, $2010: 495-510$.

35. Van Damme T, Gardeitchik T, Mohamed M, et al. Mutations in ATP6VIEl or ATP6VIA cause autosomal-recessive cutis laxa. Am J Hum Genet 2017; 100 : 216-27.

36. Jansen JC, Timal S, van Scherpenzeel M, et al. TMEM199 deficiency is a disorder of Golgi homeostasis characterized by elevated aminotransferases, alkaline phosphatase, and cholesterol and abnormal glycosylation. Am J Hum Genet 2016 ; 98 : 322-30.

37. Jansen JC, Cirak S, van Scherpenzeel M, et al. CCDC115 deficiency causes a disorder of Golgi homeostasis with abnormal protein glycosylation. Am J Hum Genet $2016 ; 98: 310-21$ 


\section{RÉFÉRENCES}

38. O'Neal SL, Zheng W. Manganese toxicity upon overexposure: a decade in review. Curr Environ Health Rep $2015 ; 2$ : 315-28.

39. Amyere M, Jaeken J, Zeevaert R, et al. TMEMI65 deficiency causes a congenital disorder of glycosylation. Am J Hum Genet 2012 ; 91 : 15-26.

40. Zeevaert R, Zegher F de, Sturiale L, et al. Bone dysplasia as a key feature in three patients with a novel congenital disorder of glycosylation (CDG) type II due to a deep intronic splice mutation in TMEM165. In : Zschocke J, Gibson KM, Brown G, et al., eds. JIMD reports - Case and research reports, 2012/5. Berlin, Heidelberg : Springer Berlin Heidelberg, 2012 : 145-52.

41. Potelle S, Morelle W, Dulary $\varepsilon$, et al. Glycosylation abnormalities in Gdtlp/TMEM165 deficient cells result from a defect in Golgi manganese homeostasis. Hum Mol Genet 2016 ; 25 : 1489-500.

42. Dulary $\varepsilon$, Potelle $S$, Legrand $D$, et al. TMEMI 65 deficiencies in congenital disorders of glycosylation type II (CDG-II): clues and evidences for roles of the protein in Golgi functions and ion homeostasis. Tissue Cell $2017 ; 49: 150-6$.

43. Dulary $\varepsilon, Y u$ SY, Houdou M, et al. Investigating the function of Gdtlp in yeast Golgi glycosylation. Biochim Biophys Acta 2017 ; 1862 : 394-402.

44. Thines $L$, Deschamps $A$, Sengottaiyan $P$, et al. The yeast protein Gdtlp transports $\mathrm{Mn}^{2+}$ ions and thereby regulates manganese homeostasis in the Golgi. J Biol Chem 2018 ; 293 : 8048-55.

45. Morelle W, Potelle S, Witters P, et al. Galactose supplementation in patients with TMEM165-CDG rescues the glycosylation defects. J Clin Endocrinol Metab 2017 ; 102 : 1375-86.

46. Potelle S, Dulary $\varepsilon$, Climer L, et al. Manganese-induced turnover of TMEM165. Biochem / 2017 ; $474:$ 1481-93.

47. Houdou M, Lebredonchel $\varepsilon$, Garat A, et al. Involvement of thapsigargin- and cyclopiazonic acidsensitive pumps in the rescue of TMEMI65-associated glycosylation defects by $\mathrm{Mn}^{2+}$. FASEB $2019 ; 33: 2669-79$.
48. Park JH, Hogrebe M, Grüneberg M, et al. SLC39A8 deficiency: a disorder of manganese transport and glycosylation. Am J Hum Genet 2015 ; 97 : 894-903.

49. Verheijen J, Tahata S, Kozicz T, et al. Therapeutic approaches in congenital disorders of glycosylation (CDG) involving $\mathrm{N}$-linked glycosylation: an update. Genet Med $2019 ; 22: 268-79$.

50. Péanne R, Lonlay P de, Foulquier F, et al. Congenital disorders of glycosylation (CDG): quo vadis? Eur J Med Genet 2017 ; 61 : 643-63.

51. Sosicka P, Ng BG, Freeze HH. Therapeutic monosaccharides: looking back, moving forward. Biochemistry 2019 ; acs.biochem.9b00565.

52. Jaeken J, Péanne R. What is new in CDG? J Inherit Metab Dis 2017 ; 40 : 569-86.

53. Brasil S, Pascoal C, Francisco R, et al. CDG therapies: from bench to bedside. Int J Mol Sci $2018 ; 19$ : 1304.

54. Park JH, Hogrebe M, Fobker M, et al. SLC39A8 deficiency: biochemical correction and major clinical improvement by manganese therapy. Genet Med $2018 ; 20: 259-68$

55. Yuste-Checa P, Brasil S, Gámez A, et al. Pharmacological chaperoning: a potential treatment for PMM2-CDG: human mutation. Hum Mutat 2017 ; 38: $160-8$

56. Martínez-Monseny AF, Bolasell M, Callejón Póo L, et al. AZATAX: acetazolamide safety and efficacy in cerebellar syndrome in PMM2 congenital disorder of glycosylation (PMM2 CDG). Ann Neurol 2019 ; 85 : $740-51$

TIRÉS À PART

M. Houdou

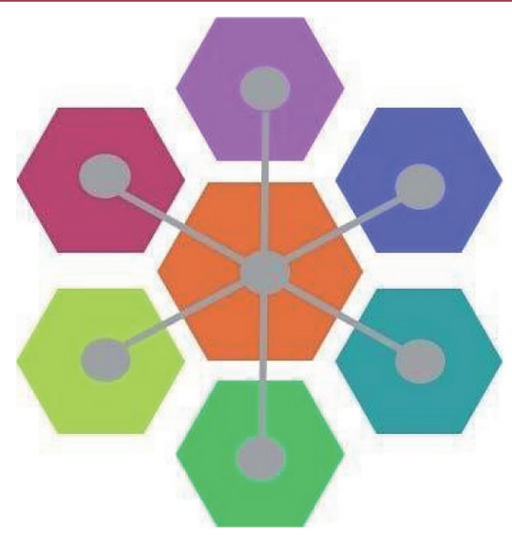

\section{Globall Registry for COL6-related dystrophies}

\section{Registre global des dystrophies} liées au collagène de type VI

S'inscrire sur : www.collagen6.org

Ou contactez-nous par e-mail à l'adresse : collagenbregistry@ncl.ac.uk

La traduction française sera bientôt disponible sur le site web.
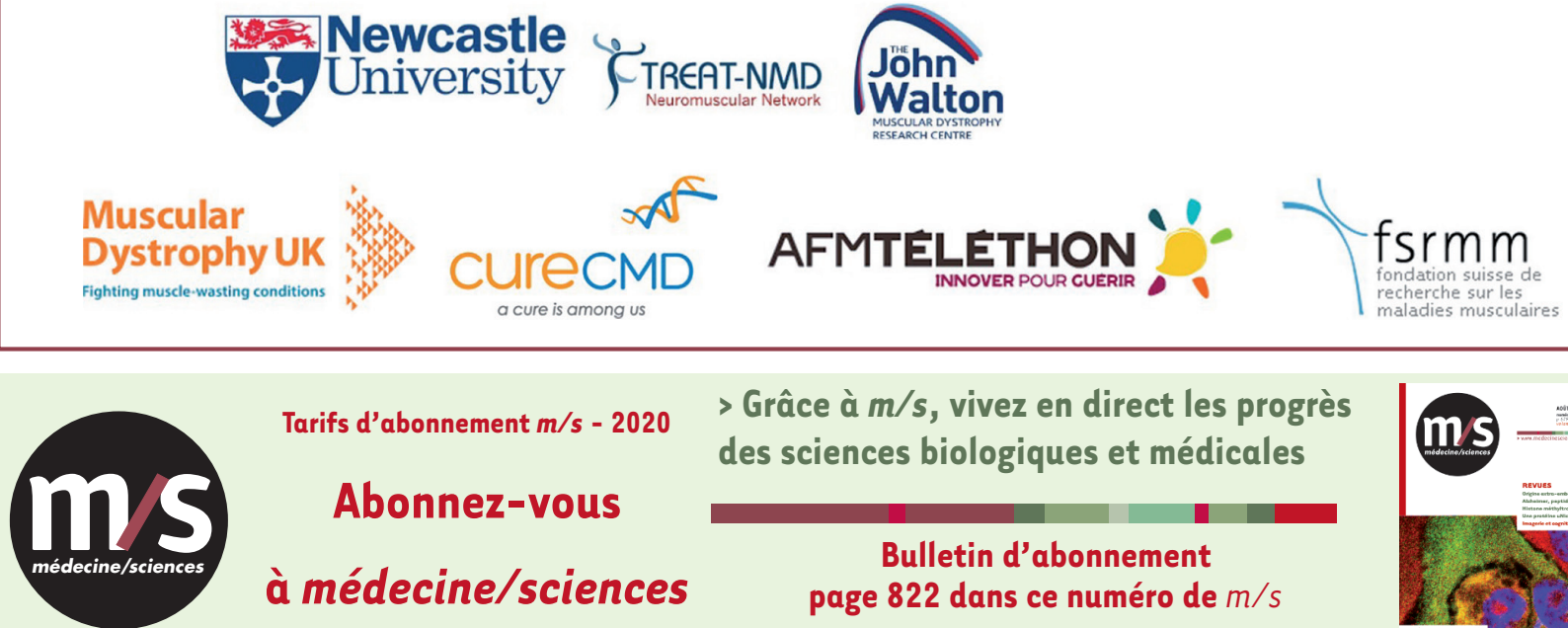

Tarifs d'abonnement $m / s-2020$

$>$ Grâce à $m / s$, vivez en direct les progrès des sciences biologiques et médicales

Abonnez-vous

à médecine/sciences

Bulletin d'abonnement page 822 dans ce numéro de $\mathrm{m} / \mathrm{s}$

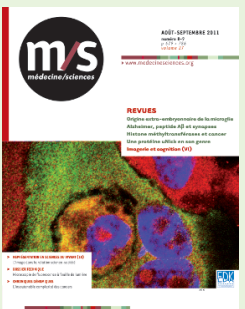

